\title{
A Novel Modular Dynamic Stabilization System for the Treatment of Degenerative Spinal Pathologies
}

\author{
Ali Fahir OZER ${ }^{1}$, Orhun Mete CEVIK², Deniz Ufuk ERBULUT ${ }^{3}$, Onur YAMAN ${ }^{1}$, Salim SENTURK ${ }^{1}$, \\ Tunc OKTENOGLU ${ }^{1}$, Mehdi SASANI ${ }^{1}$, Tuncer SUZER ${ }^{1}$, Vijay GOEL ${ }^{3}$ \\ ${ }^{1}$ Koc University, School of Medicine, Department of Neurosurgery, Istanbul, Turkey \\ ${ }^{2}$ Bakirkoy Training and Research Hospital for Psychiatric and Nervous Diseases, Department of Neurosurgery, Istanbul, Turkey \\ ${ }^{3}$ Toledo University, Departments of Bioengineering and Orthopaedic Surgery Colleges of Engineering, Toledo, USA
}

\section{ABSTRACT}

AIM: To show the preliminary clinical results of the Orthrus modular dynamic stabilization system that is a new instrumentation system intended for degenerative diseases of the lumbar spine.

MATERIAL and METHODS: The system utilizes two different types of screws that can be used in conjunction with different types of rods such as titanium, carbon fiber or PEEK. The first type of screw is a double headed screw to interconnect to the upper and lower level with independent rods. The second type of screw is a sliding screw to be used on a immovable vertebrae that allows movement in two planes on the tip.

RESULTS: The system has been used on 36 patients with pathology varying from degenerative disc disease to degenerative lumbar scoliosis. Satisfactory results have been obtained in a all 36 patients in the 12-month follow-up period.

CONCLUSION: The Orthrus dynamic system shows better clinical results than the available dynamic systems on the market. It also proves to provide similar fusion with considerably less postoperative morbidity which makes it a better method to treat adult degenerative spine diseases for carefully chosen patients.

KEYWORDS: Adult lumbar deformity, Degenerative disc disease, Lumbar degenerative stenosis, Lumbar degenerative spondylolisthesis

\section{INTRODUCTION}

$\mathrm{P}$ osterior transpedicular dynamic systems (PTDS), are being used more often each year despite the high amount of fusion assertors $(2,5,8,15,22,23)$. Our long experience with the dynamics systems have shown us that the complication rate is near to none regardless of the type of system used especially in the young adult patients under 40 years of age who undergo a single segment instrumentation $(10,11,27)$. However, like fusion, the rate of complication increases as the number of levels involved increase $(3,29)$. In this study, we present the outcomes of our own designed screw and rod system (Orthrus) used in patients with multilevel instabilities with a one-year follow up.

\section{MATERIAL and METHODS}

The Orthrus system aims to stabilize every segment in the system as a single separate segment. The system utilizes two types of screws. The first type of screw has two screw tips to connect to two rods, one going to the upper and one to the lower segment. The other type of screw is designed to prevent load on the screw body on an unmoving fused vertebra and has two types of movement on the tip (Figure 1A-C). The screws can be interconnected with titanium, carbon fiber, peek or any other rod system (Figures 2, 3).

The main method used to apply the screws is the Wiltse technique (25), with many studies conducted on it. 
Patients with multilevel chronic instability are included in the study whereas sagittal imbalance, obesity, and deep osteoporosis were used as exclusion factors.

A total of 18 male and 18 female patients operated between the years 2016 and 2017 were included in the study. The age range was between 24 and 78 while the average age was 57.9. The primary symptom of the patients requiring medical aid was pain whereas the number of patients that presented with a neurological deficit was 2 . Out of all these patients, 1 patient had isolated nerve root symptoms and 6 patients had neurogenic claudication due to narrowing of the canal.

Two-way spinal x-rays, MR and CT studies were obtained in all patients and surgery was planned based on the clinic of each patient. Radiological studies were repeated on the fourth and twelfth month and the patients were advised annual follow-ups.
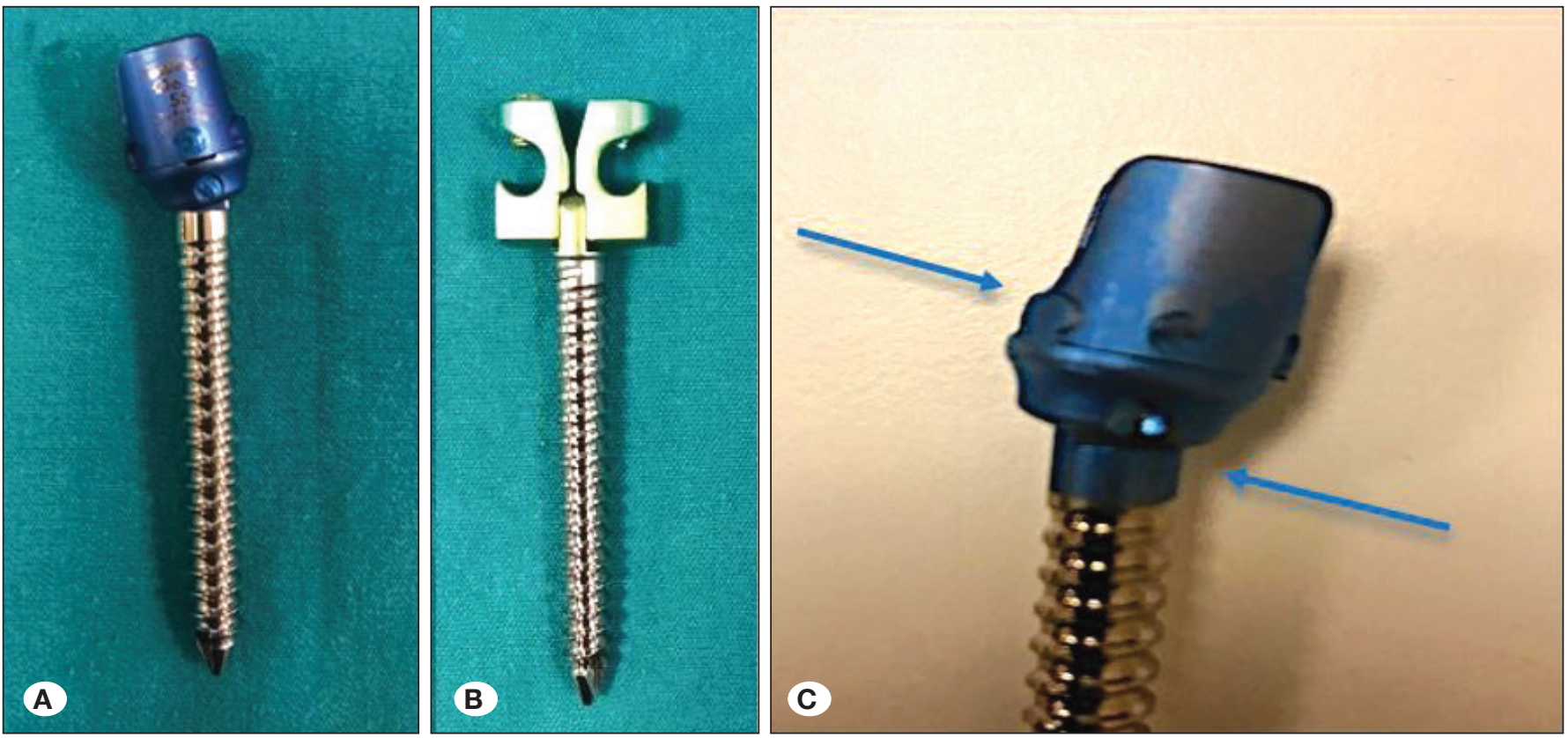

Figure 1: A, Slipping screw: Designed for sacrum or stable vertebra; B, Double-headed screw: designed for use on the mobile vertebra; $\mathbf{C}$ ) notice the sliding action on the top and bending action on the lower part of the tip.

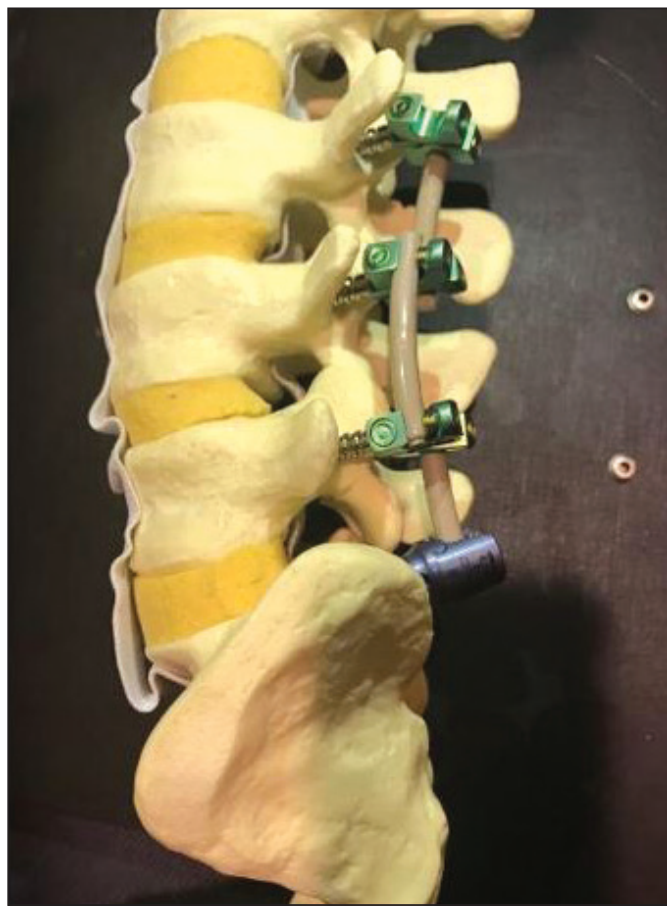

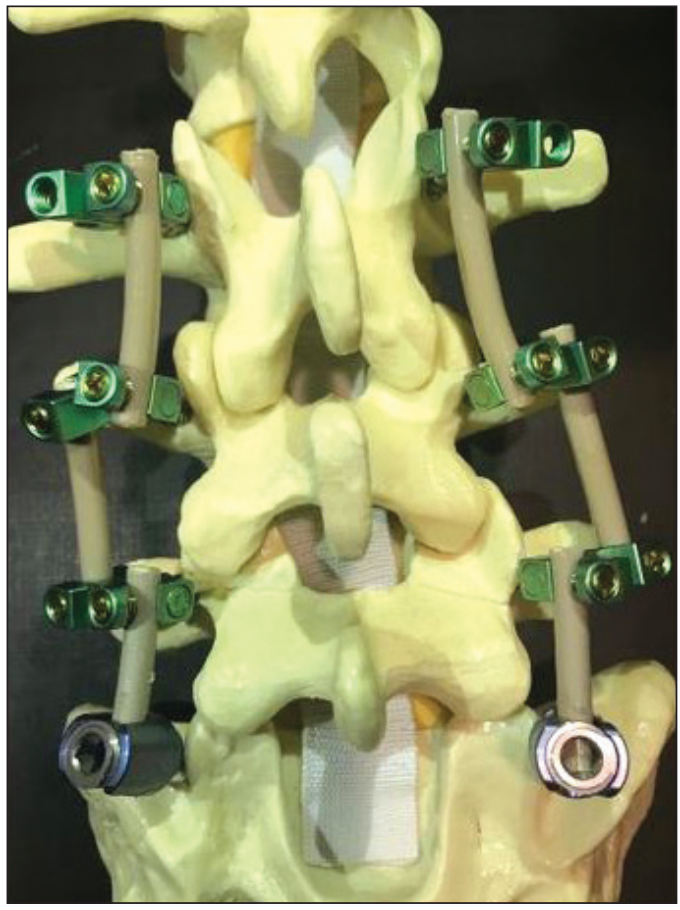

Figure 2: The Orthrus system applied to a lumbar model with 6 double headed screws on the L3, L4 and L5 vertebrae, 2 sliding screws on the S1 vertebra and 6 interconnecting PEEK rods. 


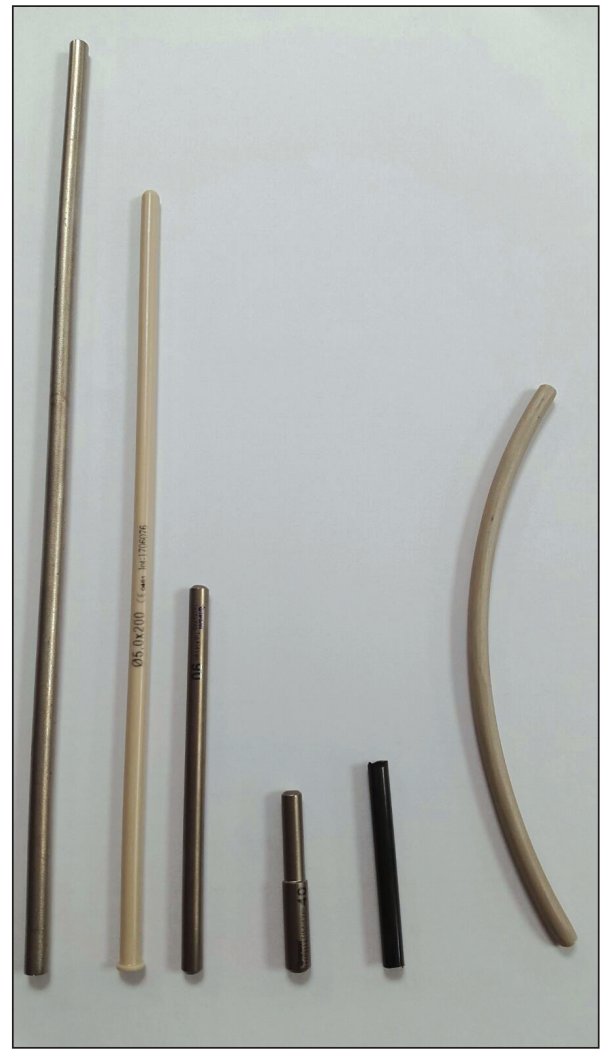

Figure 3: Various rods can be used with the Orthrus screws.
The clinical picture of the patients was quantized and assessed using the VAS and ODI.

The operations were started by decompression of the needed segments. Single level decompression was performed in 10 patients, two level decompression in 8 and three or more level decompression was performed in 8 patients. No decompression was performed in 10 patients, whereas additional microdiscectomy was performed in 6 patients. Then the midline fascia incision was closed and the Orthrus system was implemented using the Wiltse technique roughly two finger widths laterally and through the dorsal fascia and muscle group (Figure 4). Single level instrumentation with 4 screws was applied in 2 patients, two levels in 17, three levels in 8 , four or more levels in 6 and hybrid systems used in conjunction with fusion was implemented in 3 patients.

\section{RESULTS}

Satisfactory results were obtained postoperatively, and outcomes were evaluated at the sixth and twelfth months (Table I).

Radiological evaluation was done with calculation of the preoperative, fourth month and first year Cobb angle, SVA, LL-PT and PI on the whole spine x-ray. Annual follow-up was advised to the patient.

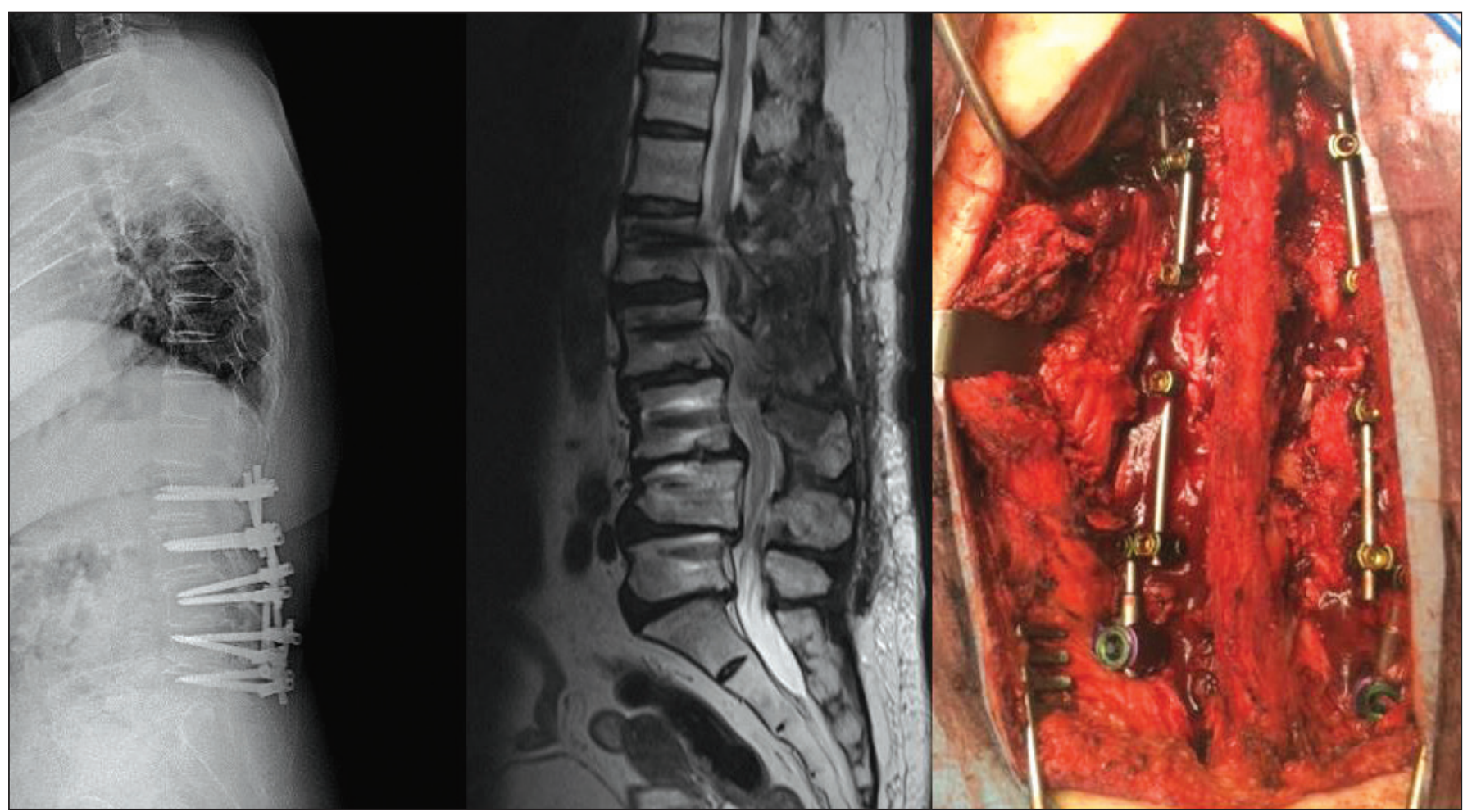

Figure 4: Postoperative X-ray (left), T2 sagittal MRI (middle) and peroperative photography (right) of the Orthrus system. Ten double headed screws were used on the L1, L2, L3, L4 and L5 vertebrae and 2 sliding screws were used on the S1 vertebra. 10 titanium rods were used to connect the screws. 


\section{DISCUSSION}

According to our clinical experience, we believe that the main reason that brings the patient to the surgeon is the back pain caused by the limited instabilities such as the glacial instability or dysfunctional segmental movements (1). Since the symptoms aggravate with movement, these patients are unable to go through the first line of conservative treatment which is back exercises. Minimally invasive procedures such as epidural steroid injections and nerve root block are used on such patients $(14,19)$. The validity of these treatments are still under investigation (20).

Another treatment modality for such patients is the minimalist approach. This modality uses mostly microsurgery but has recently moved on to endoscopic approaches (21). Although satisfactory results may be obtained postoperatively, we believe that further damaging the degenerating disc tissue or resection of the bone which is inadequately supporting stabilization in the spine will further speed up the instability, which can render the patient in a clinical condition which is worse than the preoperative state. Some complications of this approach can be named as recurrent disc herniations, post surgical spondylolistesis, recurrent lumbar canal narrowing, postoperative deformity formation in the surgical region, and progression of the degenerative deformity $(9,18)$.

Especially in the United States, the common approach is to use either fusion or minimalist methods. However, we should not forget that these patients present to the hospital with back pain as the sole symptom and maintain an uncomfortable daily life. Keeping the fusion complications in mind, which is as low as $3-4 \%$ for a single segment, more serious surgery may be needed to get the patients back up to their feet. It should not be forgotten that complication rates are much higher in multilevel instabilities.
Dynamic systems are developed especially for these patients in the grey zone, and fulfill a need using the technological advancements of the current day, and will most likely continue to thrive.

In the light of our experience, the dynamic screw and rod systems stabilize a single functional segment very near to normal as shown with both finite element methods and in laboratory studies $(6,16)$. In single segment limited instabilities, with correct indications, dynamic rod with rigid screws or vice versa or both dynamic which is our recommended system, there are no serious complications (17). We have observed an increase in complication rates as the number of segments involved increases $(4,10,28)$. The screw loosening posed a serious problem as the need for stabilization on the spine continues as opposed to the fusion systems where the instruments effect is redundant after fusion is completed $(7,8$, 13,26).

As the number segments increase, the dynamic rod introduces many variables in the system. The flexibility, load sharing and physical properties of the rods change as the length increases. This is why we tried to minimize the number of variables introduced to the system by the lengthening rod by trying to use similar lengths of the rod for a proposed system. It was then proposed that every segment should be dynamically stabilized on its own with an interconnected system.

After we came to the conclusion that a single level dynamic stabilization renders satisfactory results (12), we have queried if each level of the multisegment instability could be stabilized separately, where the system could apply similar biodynamical support to the spine when compared to a single segment of the same system. Therefore we designed this system to enable us to stabilize each segment dynamically on its own. After conducting the biomechanics studies which gave satisfactory results, we have started using the system in the

Table I: "Orthrus" Patient Compilation

\begin{tabular}{|c|c|c|c|c|c|c|c|c|}
\hline & Age & Patient & & VAS & & & ODI & \\
\hline & & & Preop & $\begin{array}{l}\text { Postop } \\
6 \text { Month }\end{array}$ & $\begin{array}{c}\text { Postop } \\
12 \text { Month }\end{array}$ & Preop & $\begin{array}{l}\text { Postop } \\
6 \text { Month }\end{array}$ & $\begin{array}{l}\text { Postop } \\
12 \text { Month }\end{array}$ \\
\hline Female Average & 62.2 & 18 & 7.0 & 2.1 & 1.2 & 65.0 & 12.8 & 6.9 \\
\hline Female Average $\Delta$ & & & & 4.9 & 5.8 & & 52.2 & 58.1 \\
\hline Male Average & 53.5 & 18 & 7.1 & 2.3 & 1.4 & 64.9 & 13.7 & 8.8 \\
\hline Male Average $\Delta$ & & & & 4.8 & 5.7 & & 51.2 & 56.1 \\
\hline Male Average Improvement & & & & $68 \%$ & $80 \%$ & & $79 \%$ & $86 \%$ \\
\hline Combined Average & 57.9 & 36 & 7.0 & 2.2 & 1.3 & 64.9 & 13.2 & 7.8 \\
\hline
\end{tabular}

ODI: Oswestry Disability Index, Postop: Postoperative, Preop: Preoperative, VAS: Visual analogue scale, $\Delta:$ Delta. 
clinic. Although our one-year results showed good outcome, we believe a three-year follow-up is necessary.

Furthermore, the system including the screws is open to further modification. In immobile segments, the main problem is the accumulation of stress on the screws and subsequent screw loosening. We therefore recommend using S2 or iliac screws in systems that extend three segments superior to split the load as the S1 screws alone will be inadequate (24).

The main complication of the dynamic systems is screw loosening. We have observed screw loosening in 2 cases out of the 36 patients operated. The patients have undergone revision surgeries with no further complications. When compared to the readily available systems, the screw loosening rates are lower (5.5\% as opposed to $19.7 \%)(13)$. It should be noted here that since the Orthrus is a modular system which has independent rods at each level, screw revision operations are easier to perform. Therefore, the duration of the operation and the surgery related morbidity and complications are reduced compared to revision surgeries of other systems.

Additionally, it should not be forgotten that this system can be used in junction with the rigid systems that are used in cases that are corrected with osteotomies. The advantage of this system is that rather than rendering the whole system motionless, the system could be extended to the needed segments and minimize the fused levels.

\section{REFERENCES}

1. Benzel EC: Biomechanics of spine stabilization. Thieme, 2011

2. Bono CM, Kadaba M, Vaccaro AR: Posterior pedicle fixationbased dynamic stabilization devices for the treatment of degenerative diseases of the lumbar spine. J Spinal Disord Tech 22(5):376-383, 2009

3. Bothmann M, Kast E, Boldt GJ, Oberle J: Dynesys fixation for lumbar spine degeneration. Neurosurg Rev 31(2):189196, 2008

4. Ciplak M, Suzer T, Senturk S, Yaman O, Sasani M, Oktenoglu T, Yilmaz A, Erbulut DU, Ozer AF: Complications of 2-level dynamic stabilization. Turk Neurosurg 2017 (Epub ahead of print)

5. Di Silvestre M, Lolli F, Bakaloudis G, Parisini P: Dynamic stabilization for degenerative lumbar scoliosis in elderly patients. Spine (Phila Pa 1976) 35(2):227-234, 2010

6. Erbulut DU, Kiapour A, Oktenoglu T, Ozer AF, GoelVK: A computational biomechanical investigation of posterior dynamic instrumentation: Combination of dynamic rod and hinged (dynamic) screw. J Biomech Eng 136(5):051007, 2014

7. Galbusera F, Volkheimer D, Reitmaier S, Berger-Roscher N, Kienle A, Wilke HJ: Pedicle screw loosening: A clinically relevant complication? Eur Spine J 24(5):1005-1016, 2015

8. Grob D, Benini A, Junge A, Mannion AF: Clinical experience with the Dynesys semirigid fixation system for the lumbar spine: Surgical and patient-oriented outcome in 50 cases after an average of 2 years. Spine (Phila Pa 1976) 30(3):324331,2005
9. Hoogland T, van den Brekel-Dijkstra K, Schubert M, Miklitz B: Endoscopic transforaminal discectomy for recurrent lumbar disc herniation: A prospective, cohort evaluation of 262 consecutive cases. Spine 33:973-978, 2008

10. Kaner T, Ozer AF: Dynamic stabilization for challenging lumbar degenerative diseases of the spine: A review of the literature. Adv Orthop 2013:753470, 2013

11. Kaner T, Sasani M, Oktenoglu T, Aydin AL, Ozer AF: Minimum two-year follow-up of cases with recurrent disc herniation treated with microdiscectomy and posterior dynamic transpedicular stabilisation. Open Orthop J 4:120-125, 2010

12. Kim $\mathrm{CH}$, Chung $\mathrm{CK}$, Jahng TA: Comparisons of outcomes after single or multilevel dynamic stabilization: Effects on adjacent segment. J Spinal Disord Tech 24(1):60-67, 2011

13. Ko CC, Tsai HW, Huang WC, Wu JC, Chen YC, Shih YH, Chen HC, Wu CL, Cheng H: Screw loosening in the Dynesys stabilization system: Radiographic evidence and effect on outcomes. Neurosurg Focus 28(6):E10, 2010

14. Lutz GE, Vad VB, Wisneski RJ: Fluoroscopic transforaminal lumbar epidural steroids: An outcome study. Arch Phys Med Rehabil 79(11):1362-1366, 1998

15. Niosi CA, Zhu QA, Wilson DC, Keynan O, Wilson DR, Oxland TR: Biomechanical characterization of the three-dimensional kinematic behaviour of the Dynesys dynamic stabilization system: An in vitro study. Eur Spine J 15(6):913-922, 2006

16. Oktenoglu T, Erbulut DU, Kiapour A, Ozer AF, Lazoglu I, Kaner T, Sasani M, Goel VK: Pedicle screw-based posterior dynamic stabilisation of the lumbar spine: In vitro cadaver investigation and a finite element study. Comput Methods Biomech Biomed Engin 18(11):1252-1261, 2015

17. Ozer AF, Crawford NR, Sasani M, Oktenoglu T, Bozkus $\mathrm{H}$, Kaner T, Aydin S: Dynamic lumbar pedicle screw-rod stabilization: Two-year follow-up and comparison with fusion. Open Orthop J 4:137-141, 2010

18. Parker SL, Mendenhall SK, Shau DN, Adogwa O, Anderson WN, Devin CJ, McGirt MJ: Minimum clinically important difference in pain, disability, and quality of life after neural decompression and fusion for same-level recurrent lumbar stenosis: Understanding clinical versus statistical significance. J Neurosurg Spine 16(5):471-478, 2012

19. Riew KD, Park JB, Cho YS, Gilula L, Patel A, Lenke LG, Bridwell $\mathrm{KH}$ : Nerve root blocks in the treatment of lumbar radicular pain: A minimum five-year follow-up. J Bone Joint Surg Am 88(8):1722-1725, 2006

20. Riew KD, Yin Y, Gilula L, Bridwell KH, Lenke LG, Lauryssen C, Goette K: The effect of nerve-root injections on the need for operative treatment of lumbar radicular pain: A prospective, randomized, controlled, double-blind study. J Bone Joint Surg Am 82-A(11):1589-1593,2000

21. Ruetten S, Komp M, Merk H, Godolias G: Full-endoscopic interlaminar and transforaminal lumbar discectomy versus conventional microsurgical technique: A prospective, randomized, controlled study. Spine (Phila Pa 1976) 33(9):931939, 2008

22. Schaeren S, Broger I, Jeanneret B: Minimum four-year followup of spinal stenosis with degenerative spondylolisthesis treated with decompression and dynamic stabilization. Spine (Phila Pa 1976) 33(18):636-642, 2008 
23. Sénégas J, Vital JM, Pointillart V, Mangione P: Clinical evaluation of a lumbar interspinous dynamic stabilization device (the Wallis system) with a 13-year mean follow-up." Neurosurg Rev 32(3):335-341, 2009

24. Tsuchiya K, Bridwell KH, Kuklo TR, Lenke LG, Baldus C: Minimum 5-year analysis of L5-S1 fusion using sacropelvic fixation (bilateral S1 and iliac screws) for spinal deformity. Spine (Phila Pa 1976) 31(3):303-308, 2006

25. Wiltse LL, Bateman JG, Hutchinson RH, Nelson WE: The paraspinalsacrospinalis-splitting approach to the lumbar spine. J Bone Joint Surg Am 50(5):919-926,1968

26. Wu JC, Huang WC, Tsai HW, Ko CC, Wu CL, Tu TH, Cheng H: Pedicle screw loosening in dynamic stabilization: Incidence, risk, and outcome in 126 patients. Neurosurg Focus 31(4):E9, 2011
27. Würgler-Hauri CC, Kalbarczyk A, Wiesli $M$, Landolt $H$, Fandino J: Dynamic neutralization of the lumbar spine after microsurgical decompression in acquired lumbar spinal stenosis and segmental instability. Spine (Phila Pa 1976) 33(3):66-72, 2008

28. Yaldiz C, Ozkal B, Guvenc Y, Senturk S, Erbulut D, Zafarparandah I, Yaman O, Solaroglu I, Ozer AF: Comparison of the rigid rod system with modular plate with the finite element analysis in short-segment posterior stabilization in the lower lumbar region.Turk Neurosurg 27(4):610-616, 2017

29. Yu SW, Yen CY, Wu CH, Kao FC, Kao YH, Tu YK: Radiographic and clinical results of posterior dynamic stabilization for the treatment of multisegment degenerative disc disease with a minimum follow-up of 3 years. Arch Orthop Trauma Surg 132(5):583-589, 2012 